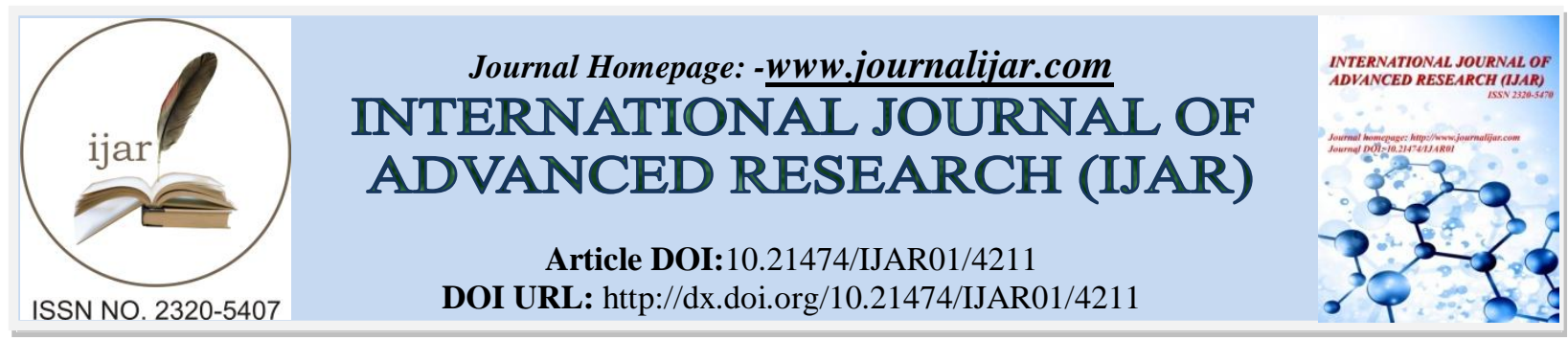

RESEARCH ARTICLE

\title{
CHARACTERISTICS OF ORO-FACIAL PAIN AMONG ADULTS ATTENDING RURAL OUTREACH ORAL HEALTH PROGRAMS IN MANGALORE, KARNATAKA.
}

\author{
Alivia Basu, Ashwini Rao*, Rajesh G, Ramya Shenoy, Mithun Pai
}

\section{Manuscript Info}

(.........................

Manuscript History

Received: 19 March 2017

Final Accepted: 17 April 2017

Published: May 2017

Key words:-

Adults, Oro-Facial Pain, Rural

Population.

\section{Abstract}

Introduction- Orofacial pain is a common complaint affecting millions of people. Studies have shown a high prevalence of pain across different regions negatively impacting individuals and communities. Identifying its characteristics goes a long way in diagnosis and treatment.

Aim- To determine the characteristics of orofacial pain among adults attending rural outreach oral health programs in Mangalore,Karnataka.

Methodology- A cross sectional study was carried out whereinformation related to demographics and characteristics of orofacial pain in terms of location, intensity, quality, duration, impact on daily activities was collected among 284 adults visiting rural outreach oral health programs in Mangalore. An oral examination was carried out to determine the cause of the orofacial pain.

Results-The prevalence of pain among patients attending rural outreach programs was $20.7 \%$ and a higher prevalence was witnessed among females. When the characteristics of pain was analyzed, $42 \%$ people had pain in lower right quadrant, 58\% had dull aching pain, 56\% patients had pain since 2-4 days, 33\% had intermittent pain and 56\% patients had pain due to pulpitis. We found that least and worst pain intensities, pain duration and cause of painwere significantly associated with impacton daily activities of the participants $(\mathrm{p}<0.05)$.

Conclusion-Higher prevalence of pain was seen in female participants and in patients having tobacco habit history, and majority of the participants had pulpitis as the cause of pain.Pain had a negative impact on the day to day activities of the participants.

Copy Right, IJAR, 2017,. All rights reserved.

\section{Introduction:-}

Dental pain indicates the presence of oral disorders as a result of dental caries, periodontal disease, dental erosion and dental trauma. ${ }^{1}$ It is a common problem affecting the lives of millions of people around the world and is the most common complaint which brings the patient to the dentist. Pain is defined as "an unpleasant sensory and emotional experience associated with actual or potential tissue damage by activation of nociceptors, which transmits a noxious stimulus to the brain." . Orofacial pain may be defined as pain localized to the region above the neck, in front of the ears and below the orbitomeatal line, as well as pain within the oral cavity. It includes pain of dental origin and temporomandibular disorders (TMDs), and thus is widely prevalent in the community. ${ }^{2}$ Even though orofacial pain is 
not a disease per se, it is characterized by a set of symptoms associated with a wide range of orofacial dysfunctions including dental caries, periodontal diseases, temporomandibular disorders, dental erosion, dental trauma and trigeminal neuralgia and studies have shown a high prevalence of pain across different regions negatively impacting individuals and communities ${ }^{3,4}$.

Additionally, specific biologic, emotional and psychological manifestations in certain individuals increase the difficulties encountered in diagnostic and management procedures. ${ }^{5}$

Pain in the orofacial region can be derived from several tissues in that region and it is therefore, necessary to determine the cause for its treatment. Many orofacial pain conditions have overlapping presentations, and diagnostic uncertainty is frequently encountered in clinical practice. ${ }^{5}$

Dental pain may cause difficulty in eating, socialization and sleep, thus diminishing work productivity and influencing the need for dental care ${ }^{6,7}$

Oro-facial problems are highly prevalent among both children and adults, although they are seldom life-threatening, many are chronic. Typically they have acute stages that are treatable and of short duration. Because of these characteristics, other chronic conditions are usually considered more serious public health problems by policy makers. $^{8}$

High prevalence of orofacial diseases and the pain it causes, is a public health concern and is related with significant morbidity and high levels of health care utilization. ${ }^{9}$

The aim of this study was to determine the characteristics of oro-facial pain among adults attending rural outreach programs in Mangalore, Karnataka.

\section{Methodology:-}

This was a cross sectional study conducted using an interview schedule, to obtain information related to demographics and characteristics of orofacial pain in terms of location, intensity, quality, duration, impact on daily activities from adults visiting rural outreach oral health programs in Mangalore. An oral examination was carried out to determine the cause of the orofacial pain.

All patients who reported to the rural outreach centres, over a duration of three months, with the primary complaint of orofacial pain were included in the study. Written informed consent was obtained from the participants.Ethical approval for conducting the study was got from the Institutional Ethics Committee.

The interview was conducted by a single examiner (principal investigator) who was calibrated before the starting of the study and the inter-examiner reliability was assessed to be 0.84 , using the Kappa statistic.Mouth mirror andCPI probe were used for the clinical examination. There were 6 items in the interview schedule. The items pertained to information about the location, intensity, quality, duration, nature and impact of pain. The intensity of pain was measured using the Numeric Pain Rating Scale where the patient was asked to make three pain ratings, corresponding to current pain intensity, least and worst pain intensity experienced over the past 24 hours. ${ }^{10} \mathrm{Clinical}$ oral examination was done using natural light with the subject sitting on a chair with a head rest.

\section{Statistical Analysis:-}

Data analysiswas done using the Statistical Package for Social Science (SPSS for Windows, version 16.0) software. Tests used were Chi square test, Independent sample t test and conditional backward logistic regression. The level of significance was kept at $\mathrm{p}<0.05$. Descriptive analysis included the prevalence, intensity and impact of dental pain.

\section{Results:-}

A total of 284 participants with a primary complaint of orofacial pain, were included in the study which was carried out over a period of three months. Out of them, 94 were male and 190female, and their mean age was 35.5 and 37 years, respectively (Fig 1). 
Tobacco habit was reported to be higher among males (41.5\%) as compared to females (8.9\%). Among the 39 males who were habituers, $35.9 \%$ used both smoking and smokeless forms of tobacco, whereas all female habituers reported use of only smokeless tobacco. This was found to be statistically significant (Table 1).

When we analyzed the characteristics of orofacial pain, we found that the most commonly affected region was the $4^{\text {th }}$ quadrant followed by the $3^{\text {rd }}$ quadrant and the $1^{\text {st }}$ quadrant. The $2^{\text {nd }}$ quadrant was the least affected. When the intensity of pain was elicited, although 8 patients reported to be suffering from severe pain, we found that most of the patients (63.4\%) reported their pain to be mild. Almost $67 \%$ reported to have dull aching pain and 8 patients could not explain the quality of pain experienced by them. (Table 2.)

Among the 284 patients, 170 visited the dentist 2-4 days after the pain started, whereas 4 female patients visited the dentist at least 10 days after the pain started. When enquired about the time of pain occurrence, 102 patients reported the pain to be intermittent in nature whereas 98 reported that the pain occurs at night. (Table 2)

When patients were interviewed regarding the least and worst pain experience once the pain started, 142 participants reported that they had experienced some period of 'no pain' even after the orofacial pain started and 132 patients reported that they had experienced either severe or moderate pain. (Table 2.)

Intensity of current pain, time of pain occurrence, least pain experienced and impact of pain on the daily activities was found to be significant ( $\mathrm{p}<0.05$ ). When we tried to determine the impact of orofacial pain on their daily activities, we found that $248(87.3 \%)$ participants reported some impact on their daily activities. (Table 2)

When we analyzed the nature of impacts, we found that $69 \%$ of participants reported that the pain affected their sleep whereas about $65 \%$ reported that it caused headache. Among males, the most often reported impact was that it affected their occupation (59.6\%) and among females it was that it affected sleep (74.7\%). The impact of orofacial pain on daily activities of the participants was significantly higher in female participants $(p<0.05)$ (Table 3$)$

When we conducted an oral examination to elicit the cause of the orofacial pain, we found that the most common cause was pulpitis (62.7\%), followed by periodontitis (26.8\%) and impacted teeth (5.6\%) (Table 4)

When conditional backward logistic regression was performed to assess the relationship between the demographic details, various characteristics of orofacial pain and the impact of pain on daily activities, it was found that gender, socio-economic status and medical history were not significantly associated ( $p>0.05)$ whereas least pain intensity, worst pain intensity, duration of pain and the cause of pain were significantly associated with pain with impact among the participants, and it had an impact on their day to day activities. ( $\mathrm{p}<0.05$ ). (Table 5).

\section{Discussion:-}

This is a representative study of adults visiting rural outreach oral health programs in Mangalore city, Karnataka.Among those affected by pain, one-third reportedmoderate pain intensity and, among them, nearly $40 \%$ referred an impact on their day-to-day activities. From the whole target population, 284 participants suffered dental pain in the fieldwork, and 205 were impacted by dental pain.

Gilbert et $\mathrm{al}^{11}$ in their study termed this impact of orofacial pain on day-to-day activities as 'oral disadvantage'. Oral disadvantage can be defined as the avoidance of certain daily activities because of decrements in oral health. These decrements include oral disease and tissue damage, pain, and functional limitation. It is best described as three factors: disadvantage due to (1) oral disease/tissue damage, (2) oral pain, and (3) oral functional limitation. In their study it was seen that, females were more likely to report disadvantage due to disease/tissue damage, and middleaged persons and irregular dental attenders were more likely to report oral disadvantage due to pain.

With regard to daily activities disrupted by dentalpain, $38.0 \%$ of the subjects reported difficulty inchewing certain types of foods, a finding that mirrorsthe results presented by Constanteet $\mathrm{al}^{1}$ and Locker and Grushka ${ }^{12}$, who reported that $30.6 \%$ of their respondentshad the same difficulty.

Oberoi et $\mathrm{al}^{13}$ in their study reported toothache to be the most common cause of orofacial pain among all the other orofacial pain symptoms. It was also seen in their study that the mean pain intensity was reported to be more among females than in males. 
Another characteristic that could contribute towards the discrepancies is the high degree of subjectivity in the perception of pain. Cognitive factors such as knowledge, beliefs and expectations, and also cultural factors, have been associated with differences in the perception of pain ${ }^{14}$.

In a study by Shetty et $\mathrm{al}^{15}$ higher prevalence of orofacial pain was witnessed among the female patient group. Most prevalent reason for orofacial pain in the subjects observed was pulpitis with 946 or $43 \%$ of the patients. TMJ dysfunction, neuralgia and others-namely neoplastic were the least observed. These findings were in accordance with our study results.

We also found that $21.0 \%$ ofthe subjects could not work because of dental painand the same amount could not sleep. Difficultiesin sleeping and socializing have also been reportedby Gilbert et $\mathrm{al}^{11}$ and McMillan et al ${ }^{16}$. The impact of dental painbrings psychosocial, physical and economic consequences, which may reduce the concentration at work, leading to low work productivity or work. Almost $13.0 \%$ of those who reported dental painindicated it was of highest intensity. For those whoreported any activity impaired by dental pain, asexpected, the average of the pain intensity washigher, reaching 70.3 in the numerical scale. Somestudies also showed that those with moderate tosevere pain were more likely to experience anactivity disrupted in some way ${ }^{16,17}$.

Orofacial pain affected the overall quality of life (QoL) and the oral health related quality of life (OHRQoL) to a great extent among the participants in a study done by Zheng et $\mathrm{al}^{18}$, and it was seen that various factors were associated with higher score of Oral Health Impact Profile (OHIP) among them suggesting higher intensity of orofacial pain.

The gender difference canbe attributed to the fact that women have a moresensitive perception of oral health, seek dental servicesmore often and report more pain than men ${ }^{19,20}$. Social/cultural and environmental factors may also predispose women to report health problems more frequently than men, including pain $^{21}$.

Durham et $\mathrm{al}^{22}$ conducted a study to describe and model current care pathways for orofacial pain patients, identify the areas where current pathways could be modified, and model whether these changes would improve outcomes for patients and use resources more efficiently. The reason orofacial patients require and use resources is because the care system they experience fails to provide them with clear and defined pathways of care based upon early diagnosis and appropriate management. The need for early diagnosis and management is key given that those with a propensity for developing psychological comorbidities may develop these sooner if diagnosis is delayed or there is a misdiagnosis causing uncertainty or anxiety over the nature of the complaint. Any psychological comorbidities that develop will then negatively impact on their prognosis.

Gupta et $\mathrm{al}^{23}$ conducted a study on quantitative overview of research on orofacial pain in Indian scenario by using bibliometric techniques on recent scientific publications on orofacial pain, and they concluded that taking into account the manpower available, research productivity in India in the field of orofacial pain is in its zygotic stages.

\section{Conclusion:-}

Higher prevalence of orofacial pain was witnessed among the female participants and the most common reason for orofacial pain among the subjects observed was pulpitis. Participants having history of tobacco use presented with higher pain intensity.Preventive measures directed to the main causes of dental pain, such as dental caries are known, effective and should be implemented. Inequalities between socio-economic groups found in this study should be taken into account, as the impact of dental pain leads to reduced daily activities and might have an effect on the quality of life. 
Figure 1:-Distribution of participants according to gender

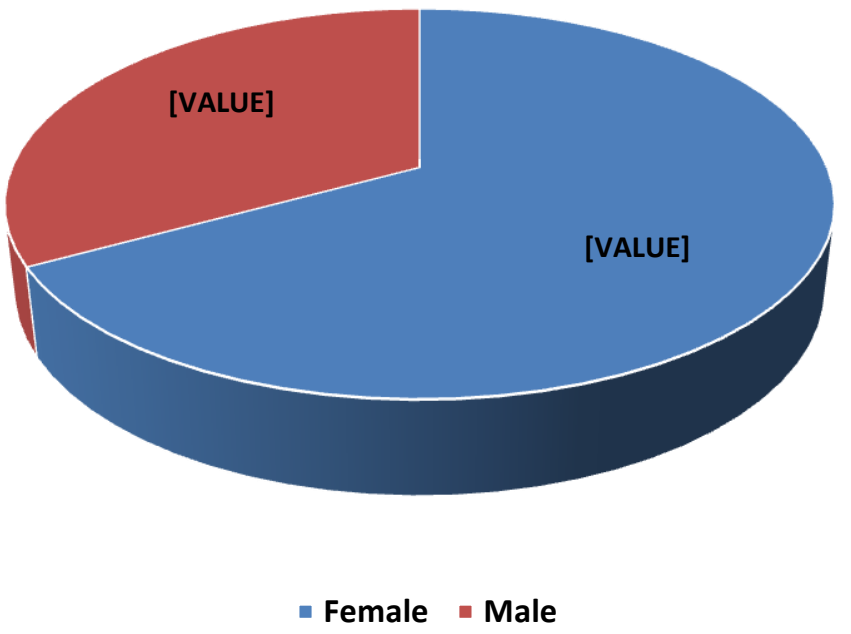

Table 1:-Characteristics of tobacco use among the participants

\begin{tabular}{|l|c|c|c|c|}
\hline & $\begin{array}{c}\text { Males } \\
(\mathbf{n = 9 4})\end{array}$ & $\begin{array}{c}\text { Females } \\
(\mathbf{n = 1 9 0 )}\end{array}$ & $\begin{array}{c}\text { Total } \\
(\mathbf{n = 2 8 4})\end{array}$ & \multirow{2}{*}{$0.001^{*}$} \\
\cline { 1 - 3 } Habit history present & $39(41.5)$ & $17(8.9)$ & $56(19.7)$ & \multirow{2}{*}{} \\
\hline Only Smoking & $23(59)$ & 0 & 23 & 19 \\
\hline Only Smokeless/ chewing type & $2(5.1)$ & $17(100)$ & 14 & \\
\hline Both types & $14(35.9)$ & 0 & \multicolumn{1}{|c|}{} \\
\hline
\end{tabular}

(Numbers in parenthesis represent percentages)

$* p<0.05$

Table 2:-Characteristics of oro-facial pain among the participants

\begin{tabular}{|c|c|c|c|c|c|}
\hline & & $\begin{array}{l}\text { Males } \\
(n=94)\end{array}$ & $\begin{array}{c}\text { Females } \\
(n=190)\end{array}$ & $\begin{array}{c}\text { Total } \\
(\mathbf{n}=\mathbf{2 8 4})\end{array}$ & $\begin{array}{c}P \text { - } \\
\text { value }\end{array}$ \\
\hline \multirow{4}{*}{ Location of pain } & $1^{\text {st }}$ Quadrant & $12(12.8)$ & $32(16.8)$ & 44 & \multirow[t]{4}{*}{0.24} \\
\hline & $2^{\text {nd }}$ Quadrant & $10(10.6)$ & $28(14.7)$ & 38 & \\
\hline & $3^{\text {rd }}$ Quadrant & $34(36.2)$ & $48(25.3)$ & 82 & \\
\hline & $4^{\text {th }}$ Quadrant & $38(40.4)$ & $82(43.2)$ & 120 & \\
\hline \multirow{4}{*}{ Intensity of current pain } & No pain & $6(6.4)$ & $8(4.2)$ & 14 & \multirow{4}{*}{$0.001 *$} \\
\hline & Mild pain & $64(68.1)$ & $116(61.1)$ & 180 & \\
\hline & Moderate pain & $24(25.5)$ & $58(30.5)$ & 82 & \\
\hline & Severe pain & 0 & $8(4.2)$ & 8 & \\
\hline \multirow[t]{4}{*}{ Quality of pain } & Throbbing & $22(23.4)$ & $36(18.9)$ & 58 & \multirow[t]{4}{*}{0.19} \\
\hline & Sharp pain & $10(10.6)$ & $18(9.5)$ & 28 & \\
\hline & Dull aching & $62(66)$ & $128(67.4)$ & 190 & \\
\hline & Cannot be explained & 0 & $8(4.2)$ & 8 & \\
\hline \multirow{4}{*}{ Duration of pain } & One day & $20(21.3)$ & $48(25.3)$ & 68 & \multirow[t]{4}{*}{0.08} \\
\hline & 2-4 days & $54(57.4)$ & $116(61.1)$ & 170 & \\
\hline & 4-7 days & $20(21.3)$ & 22 (11.6) & 42 & \\
\hline & 10 days and more & 0 & $4(2.1)$ & 4 & \\
\hline \multirow[t]{4}{*}{ Time of pain occurrence } & After eating & $8(8.5)$ & $16(8.4)$ & 24 & \multirow[t]{4}{*}{$0.03^{*}$} \\
\hline & Night & $22(23.4)$ & $76(40)$ & 98 & \\
\hline & Intermittent & $42(44.7)$ & $60(31.6)$ & 102 & \\
\hline & Continuous & $22(23.4)$ & $38(20)$ & 60 & \\
\hline Least pain experienced & No pain & $50(53.2)$ & $92(48.4)$ & 142 & $0.001 *$ \\
\hline
\end{tabular}




\begin{tabular}{|c|c|c|c|c|c|}
\hline & Mild pain & $44(46.8)$ & $82(43.2)$ & 85 & \\
\hline & Moderate pain & 0 & $16(8.4)$ & 16 & \\
\hline \multirow[t]{3}{*}{ Worst pain experienced } & Mild pain & $4(4.2)$ & $16(8.4)$ & 20 & \multirow[t]{3}{*}{0.11} \\
\hline & Moderate pain & $50(53.2)$ & $82(43.2)$ & 132 & \\
\hline & Severe pain & $40(42.6)$ & $92(48.4)$ & 132 & \\
\hline \multirow{2}{*}{$\begin{array}{l}\text { Impact of painon the daily } \\
\text { activities }\end{array}$} & Yes & $90(95.7)$ & $158(83.2)$ & 248 & \multirow[t]{2}{*}{$0.001 *$} \\
\hline & No & $4(4.3)$ & $32(16.8)$ & 36 & \\
\hline
\end{tabular}

(Numbers in parenthesis represent percentages)

$* \mathrm{p}<0.05$

Table 3:-Impact of oro-facial pain on the daily activities of the participants

\begin{tabular}{|l|c|c|c|}
\hline & $\begin{array}{c}\text { Males } \\
(\mathbf{n = 9 4 )}\end{array}$ & $\begin{array}{c}\text { Females } \\
(\mathbf{n = 1 9 0})\end{array}$ & $\begin{array}{c}\text { Total } \\
(\mathbf{n = 2 8 4})\end{array}$ \\
\hline Affected sleep & $54(57.4)$ & $142(74.7)$ & $196(69)$ \\
\hline Affected talking & $40(42.6)$ & $62(32.6)$ & $102(35.9)$ \\
\hline Affected their occupation & $56(59.6)$ & $98(51.6)$ & $154(54.2)$ \\
\hline Affected house hold work & $32(43.2)$ & $42(22.1)$ & $74(26.1)$ \\
\hline Caused headache & $54(34)$ & $1308.4)$ & $184(64.8)$ \\
\hline
\end{tabular}

$$
\begin{aligned}
& \text { (Numbers in parenthesis represent percentages) } \\
& * \mathrm{p}<0.05
\end{aligned}
$$

Table 4:-Causes of oro-facial pain among the participants

\begin{tabular}{|l|c|c|c|}
\hline & $\begin{array}{c}\text { Males } \\
(\mathbf{n = 9 4 )}\end{array}$ & $\begin{array}{c}\text { Females } \\
(\mathbf{n = 1 9 0})\end{array}$ & $\begin{array}{c}\text { Total } \\
(\mathbf{n = 2 8 4})\end{array}$ \\
\hline Pulpitis & $56(59.6)$ & $122(64.2)$ & $178(62.7)$ \\
\hline Periodontitis & $22(23.4)$ & $54(28.4)$ & $76(26.8)$ \\
\hline Pericoronitis & 0 & $6(3.2)$ & $6(2.1)$ \\
\hline TMJ disorders/conditions & $6(6.4)$ & $2(1.1)$ & $8(2.8)$ \\
\hline Impacted teeth & $10(10.6)$ & $6(3.1)$ & $16(5.6)$ \\
\hline
\end{tabular}

(Numbers in parenthesis represent percentages)

\begin{tabular}{|c|c|c|}
\hline & Pain with impact & P-value \\
\hline Location of pain & $\begin{array}{l}1^{\text {st }}-40(14) \\
2^{\text {nd }}-30(11) \\
3^{\text {rd }}-76(27) \\
4^{\text {th }}-114(40) \\
\end{array}$ & 0.18 \\
\hline Least pain intensity & $\begin{array}{l}\text { No }-120(42) \\
\text { Mild }-124(44) \\
\text { Moderate }-16(5.6)\end{array}$ & $0.014 *$ \\
\hline Worst pain intensity & $\begin{array}{l}\text { Mild - } 20(7) \\
\text { Moderate }-110(39) \\
\text { Severe }-130(46)\end{array}$ & $0.023 *$ \\
\hline Pain quality & $\begin{array}{l}\text { Throbbing- } 58(20) \\
\text { Sharp- } 28(10) \\
\text { Dull aching-166 (58.5) } \\
\text { Others- } 8(3)\end{array}$ & 0.09 \\
\hline Duration of pain & $\begin{array}{l}\text { 1st day- } 68(24) \\
2-4 \text { days-160 (56) } \\
4-7 \text { days- } 32(11) \\
10 \text { days or more - } 0\end{array}$ & $0.00 *$ \\
\hline Time of occurrence & $\begin{array}{l}\text { After eating- } 10(7) \\
\text { Night- } 43(30) \\
\text { Intermittent- } 47(33) \\
\text { Continuous- } 30(21)\end{array}$ & 0.19 \\
\hline
\end{tabular}

Table 5:-Relationship between characteristics of oro-facial pain and presence/absence of impact 


\begin{tabular}{|l|l|l|}
\hline Cause of pain & Pulpitis - 80 (56) & $0.001^{*}$ \\
& Periodontitis - 35 (24.5) & \\
& Pericoronitis - 3(2) & \\
& TMJ problems - 4 (3) & \\
& Impacted tooth $-8(6)$ & \\
\hline
\end{tabular}

(Numbers in parenthesis represent percentages)

$* \mathrm{p}<0.05$

\section{References:-}

1. Constante HM, Bastos JL, Peres KG, Peres MA. Socio-demographic and behavioural inequalities in the impact of dental pain among adults: a population-based study. Community Dent Oral Epidemiol 2012; 40: 498-506

2. Merril RL. Central mechanisms of orofacial pain. Dent Clin North Am 2007; 51: 45-59.

3. Pau AK, Croucher R, Marcenes W. Prevalence estimates and associated factors for dental pain: a review. Oral Health Prev Dent 2003;1: 209-20.

4. Daly B, Watt R, Batchelor P, Treasure E. Essential dental public health. Oxford: Oxford University Press, 2002; P8.

5. Shephard MK, McGregor EA, Zakrzewska JM. Orofacial Pain: A guide for the headache physician. Headache 2014;54: 22-39

6. Peek CW, Gilbert GH, Duncan RP. Predictors of chewing difficulty onset among dentate adults: 24-month incidence. J Public Health Dent 2002;62:214-21.

7. Cohen LA, Bonito AJ, Akin DR, Manski RJ, Macek MD, Edwards RR et al. Toothache pain: behavioural impact and self-care strategies. Spec Care Dentist 2009;29: 85-95.

8. Reisine ST. Dental health and public policy: the social impact of dental disease. Am J Public Health 1985; 75:27-30.

9. Gomes AS, Abegg C. The impact of oral health on daily performance of municipal waste disposal workers in Porto Alegre, Rio Grande do Sul State, Brazil. Cad SaúdePu'blica 2007; 23:1707-14

10. McCafferyM , Beebe A, et al. Pain: Clinical Manual for Nursing Practice. St Louis, Missouri: Mosby’s Inc; 1989 .

11. Gilbert GH, Duncan RP, Heft MW, Dolan TA, Vogel WB. Oral disadvantage among dentate adults. Community Dent Oral Epidemiol 1997;25:301-13.

12. Locker D, Grushka M. The impact of dental and facial pain. J Dent Res 1987;66:1414-7.

13. Oberoi SS, Hiremath SS, Yashoda R, Marya C, Rekhi A. Prevalence of Various Orofacial Pain Symptoms and Their Overall Impact on Quality of Life in a Tertiary Care Hospital in India. J Maxillofac Oral Surg. 2014 Dec;13(4):533-8

14. Lacerda JT, Simionato EM, Peres KG, Peres MA, Traebert J, Marcenes W. Dental pain as the reason for visiting a dentist in a Brazilian adult population. Rev SaudePublica 2004; 38:453-8

15. Shetty A, James L, Nagaraj T, Abraham M. Epidemiology of orofacial pain: A retrospective study. J AdvClin Res Insights 2015; 2:12-15.

16. McMillan AS, Wong MC, Zheng J, Lam CL. The consequences of orofacial pain symptoms: a populationbased study in Hong Kong. Community Dent Oral Epidemiol 2008;36:417-24.

17. Alexandre GC, Nadanovsky P, Lopes CS, Faerstein E. Prevalence and factors associated with dental pain that prevents the performance of routine tasks by civil servants in Rio de Janeiro. Cad Sau'dePu'blica 2006;22:1073-8.

18. Zheng J, Wong MC, Lam CL. Key factors associated with oral health-related quality of life (OHRQOL) in Hong Kong Chinese adults with orofacial pain. J Dent. 2011;39(8):564-71

19. Liddell A, Locker D. Gender and age differences in attitudes to dental pain and dental control. Community Dent Oral Epidemiol 1997;25:314-8.

20. McGrath C, Bedi R. Gender variations in the social impact of oral health. J Ir Dent Assoc 2000;46:87-91.

21. MacFarlane TV, Blinkhorn AS, Davies RM, Kincey J, Worthington HV. Oro-facial pain in the community: prevalence and associated impact. Community Dent Oral Epidemiol 2002;30:52-60

22. Durham J, Breckons M, Araujo-Soares V, Exley C, Steele J, Vale L. Developing Effective and Efficient care pathways in chronic Pain: DEEP study protocol. BMC Oral Health. 2014; 14: 6.

23. Gupta M, Srinivas K, Reddy SBH, Krishna HJJ. Research on Orofacial pain in India: A bibliometric study. J Indian Aca Oral Med Radiol 2012; 24(4): 292-295. 